\author{
SANDIA REPORT \\ SAND2007-5025 \\ Unlimited Release \\ Printed July 2007
}

\title{
Test Definitions for the Evaluation of Seismic Sensors
}

\section{Version 1.0}

Richard P. Kromer, Darren M. Hart and James M. Harris

Prepared by

Sandia National Laboratories

Albuquerque, New Mexico 87185 and Livermore, California 94550

Sandia is a multiprogram laboratory operated by Sandia Corporation, a Lockheed Martin Company, for the United States Department of Energy's

National Nuclear Security Administration under Contract DE-AC04-94AL85000.

Approved for public release; further dissemination unlimited.

\section{Sandia National Laboratories}


Issued by Sandia National Laboratories, operated for the United States Department of Energy by Sandia Corporation.

NOTICE: This report was prepared as an account of work sponsored by an agency of the United States Government. Neither the United States Government, nor any agency thereof, nor any of their employees, nor any of their contractors, subcontractors, or their employees, make any warranty, express or implied, or assume any legal liability or responsibility for the accuracy, completeness, or usefulness of any information, apparatus, product, or process disclosed, or represent that its use would not infringe privately owned rights. Reference herein to any specific commercial product, process, or service by trade name, trademark, manufacturer, or otherwise, does not necessarily constitute or imply its endorsement, recommendation, or favoring by the United States Government, any agency thereof, or any of their contractors or subcontractors. The views and opinions expressed herein do not necessarily state or reflect those of the United States Government, any agency thereof, or any of their contractors.

Printed in the United States of America. This report has been reproduced directly from the best available copy.

Available to DOE and DOE contractors from

U.S. Department of Energy

Office of Scientific and Technical Information

P.O. Box 62

Oak Ridge, TN 37831

Telephone: $\quad$ (865) 576-8401

Facsimile: $\quad$ (865) 576-5728

E-Mail: reports@adonis.osti.gov

Online ordering: http://www.osti.gov/bridge

Available to the public from

U.S. Department of Commerce

National Technical Information Service

5285 Port Royal Rd.

Springfield, VA 22161

Telephone: $\quad$ (800) 553-6847

Facsimile: (703) 605-6900

E-Mail: $\quad$ orders@ntis.fedworld.gov

Online order: $\quad$ http://www.ntis.gov/help/ordermethods.asp?loc=7-4-0\#online

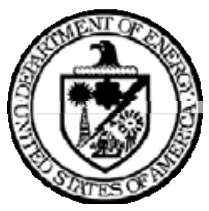


SAND2007-5025

Unlimited Release

Printed July 2007

\title{
Test Definitions For the Evaluation of Seismic Sensors
}

\author{
Richard P. Kromer \\ R.P. Kromer Consulting \\ 5309 Dee Drive NE \\ Albuquerque, New Mexico 87111-1905 \\ and \\ Darren M. Hart and James M. Harris \\ Ground-based Monitoring R and E \\ Sandia National Laboratories \\ P.O. Box 5800 \\ Albuquerque, New Mexico 87185
}

\begin{abstract}
Most test methodologies referenced in this Test Definition and Test Procedures were designed by Sandia specifically for geophysical instrumentation evaluation. When appropriate, test instrumentation calibration is traceable to the National Institute for Standards Technology (NIST).
\end{abstract}




\section{CONTENTS}

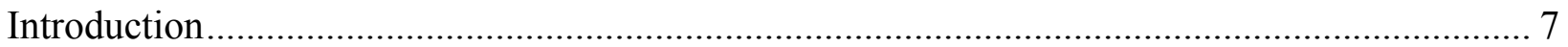

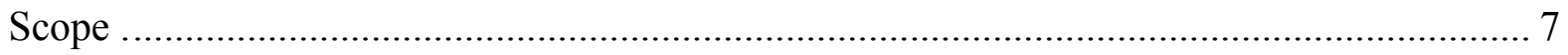

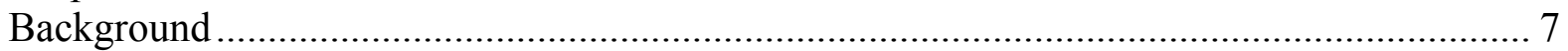

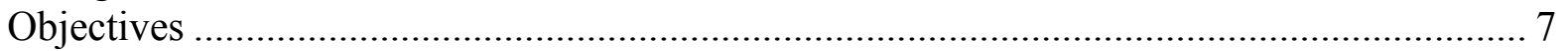

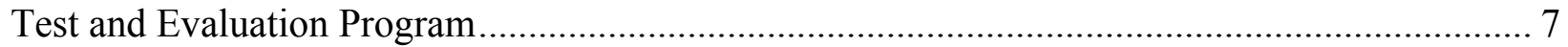

Test and Evaluation Background .............................................................................. 7

Seismic Sensor Tests................................................................................................ 7

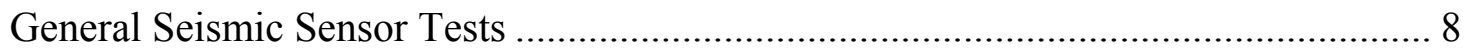

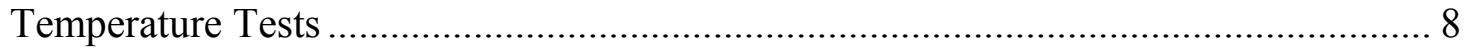

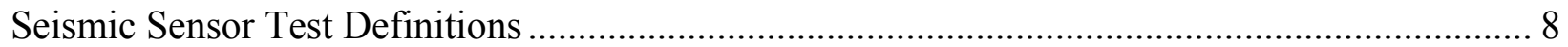

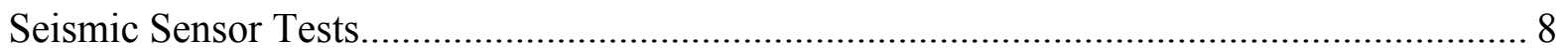

Seismic Sensor Characterization .................................................................. 8

Seismic Sensor Performance Tests.................................................................... 8

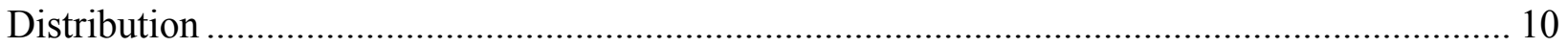




\section{Scope}

\section{INTRODUCTION}

This Test Definition and Test Procedures for the Evaluation of seismic sensors defines the process that can be performed as part of the evaluation and testing of geophysical sensors, digitizers, sensor subsystems and geophysical station/array systems.

\section{Background}

A seismic sensor can consist of a single axis individual element or a combination of individual elements. The single axis element can usually be configured as a vertical or horizontal element. The three axis element usually contains a vertical element and two horizontal elements all aligned orthogonal to each other. Other mechanical configurations mathematically rotate the data to vertical and horizontal components. The seismic sensors are usually built to be installed in a seismic vault or deployed in a posthole or borehole. The interface to the earth is usually through attached feet, a borehole lock or can be buried in sand. The seismic element converts ground motion to analog signals. The analog signals are sent to a Digitizing Waveform Recorder (DWR) to be either stored on local recording media or sent to a central recording facility for storage and/or analysis. Digital seismic sensors, sensor and digitizer integrated in the same package, output data in digital form. The seismic sensor usually provides a mechanism for external calibration of the sensor or an indication of operational capability. The sensor output can be a voltage representation of units of velocity, acceleration or a combination.

\section{Objectives}

The objectives are to evaluate the overall technical performance of the seismic sensor and provide a general performance check of the calibration capability.

The results of these evaluations can be compared to the manufacturer's specifications and any relevant application requirements or specifications.

\section{TEST AND EVALUATION PROGRAM}

\section{Test and Evaluation Background}

Sandia National Laboratories (SNL) Ground-based Monitoring R\&E Department has the capability of evaluating the performance of seismic sensors for geophysical applications.

\section{Seismic Sensor Tests}

The following set of tests has been developed to evaluate seismic sensor performance.

\section{Sensors with Internal Pre-amplifiers}

Some sensors may have internal preamplifiers. Some may have external or separate preamplifiers to match the sensitivity of an application sensor to a DWR. Some sensors may depend on the DWR to provide sufficient gain for the required application. The analog amplifier/preamplifier is considered to be part of the sensor for this test plan.

\section{Sensors with Internal Digitizer}

Some sensors may have internal high resolution digitizers. The sensor may be a true digital sensor with the digitizer designed into the sensor feedback electronics or a separate digitizer integrated to the sensor analog output in the same package. Both types of sensors have digital output with internal or external data clock to 
provide a digital output. The actual response of the true digital sensor may be difficult to determine. The response of the integrated sensor/digitizer is determined by the response of each component.

\author{
General Seismic Sensor Tests \\ Seismic Sensor Characterization \\ Response Model Determination \\ Seismic Sensor Performance Tests \\ Seismic Sensor Self-Noise (SS-SN) \\ Seismic Sensor Response Verification (SS-RV) \\ Seismic Sensor Calibration Response (SS-CR)
}

\title{
Temperature Tests
}

Seismic sensors with sub-nanometer resolution can be affected by small temperature changes. A sensor may be required to operate over a range of environments from arctic to desert. Also, depending on the type of installation, the seasonal and diurnal variation can be significant. Tests can be performed at SNL to determine the sensor's sensitivity to temperature over a range from $-65^{\circ} \mathrm{C}$ to $+125^{\circ} \mathrm{C}$.

Temperature testing can be performed at the high and low end of the manufacturer's temperature specifications or over the range for the application requirements. Unless otherwise specified, the temperature is changed slowly and the sensors internal temperature is allowed to stabilize before testing.

\section{SEISMIC SENSOR TEST DEFINITIONS}

\section{Seismic Sensor Tests}

\section{Seismic Sensor Characterization}

The seismic sensor will be characterized using manufacturer supplied data to determine sensor gain, sensor bandwidth, theoretical self-noise and output impedance. Ability to calibrate is determined. All factory data should lead to a mathematical response model and calibration transfer response.

\section{Seismic Sensor Performance Tests}

Seismic signals are used as test stimuli to measure sensor performance. Sensor nonlinearities add to the self-noise of the sensor.

\section{Seismic Sensor Self- Noise (SS-SN)}

Purpose: The purpose of the seismic sensor self-noise test is to determine the sensor self-noise in the presence of low seismic background signals.

Configuration: Two or more sensors are installed side-by-side in a seismic vault or stacked vertically in a borehole. The sensor outputs are connected to a data acquisition system that samples the data synchronously. Data are acquired during low seismic backgrounds.

Evaluation: Coherence analysis noise-power computation provides the noise-floor of the sensor pair for low seismic background stimulus. If three or more sensors are available, the use of Three-Channel Correlation Analysis techniques can derive individual sensor responses and self-noise.

\section{Seismic Sensor Response Verification (SS-RV)}

Purpose: The purpose of the seismic sensor response verification test is to verify the seismic sensor sensitivity and response using seismic background signals and a reference seismic sensor. 
Configuration: A characterized reference sensor and one or more of the sensors under test, are installed side-by-side in a seismic vault or in an adjacent borehole. The seismic sensor outputs are connected to a data acquisition system that samples the data synchronously. Data are acquired during moderate seismic backgrounds and events.

Evaluation: Convert the data from each seismic sensor to ground motion using the sensor response mathematical model for each sensor. If the sensor response models are correct, the amplitude response measurements in earth-motion units will be identical.

\section{Seismic Sensor Calibration Response (SS-CR)}

Purpose: The purpose of the seismic calibration response verification test is to verify the seismic sensor calibration transfer response using voltage or current signals from a signal generator.

Calibration signals can be flat to velocity or acceleration.

Configuration: Sensor outputs are connected to a data acquisition system that samples the data synchronously. Use sensor appropriate method for initiating electronics step or other calibration signal.

Evaluation: Use analysis method appropriate to input calibration signal type to extract sensor transfer function and gain for sensor under test. 


\section{DISTRIBUTION}

1 Leslie Casey

NNSA Office of Nonproliferation Research and Development/NA-22

1000 Independence Avenue SW

Washington, DC 20585

1 Joe Schrodt

Air Force Technical Applications Center/TTR

1030 South Highway A1A

Patrick AFB, FL 32925-3002

$\begin{array}{llll}1 & \text { MS0404 } & \text { John Merchant } & 05736 \\ 1 & \text { MS0404 } & \text { Eric Chael } & 05736 \\ 1 & \text { MS0404 } & \text { Mark Harris } & 05736 \\ 1 & \text { MS0404 } & \text { Darren Hart } & 05736 \\ 1 & \text { MS0404 } & \text { Bobby Corbell } & 05736\end{array}$

2 MS9018 Central Technical Files 8944

2 MS0899 Technical Library 9536 